\title{
Synaptically Driven Calcium Transients via Nicotinic Receptors on Somatic Spines
}

\author{
Richard D. Shoop, ${ }^{1}$ Karen T. Chang, ${ }^{1}$ Mark H. Ellisman, ${ }^{2,3}$ and Darwin K. Berg ${ }^{1}$ \\ Departments of ${ }^{1}$ Biology and ${ }^{2}$ Neurosciences and the ${ }^{3}$ National Center for Microscopy and Imaging Research, University \\ of California, San Diego, La Jolla, California 92093-0357
}

\begin{abstract}
Dendritic spines commonly receive glutamatergic innervation at postsynaptic densities and compartmentalize calcium influx arising from synaptic signaling. Recently, it was shown that a class of nicotinic acetylcholine receptors containing $\alpha 7$ subunits is concentrated on somatic spines emanating from chick ciliary ganglion neurons. The receptors have a high relative calcium permeability and contribute importantly to synaptic currents, although they appear to be excluded from postsynaptic densities. Here we show that low-frequency synaptic stimulation of the $\alpha 7$-containing receptors induces calcium transients confined to the spines. Highfrequency stimulation induces a transient calcium elevation in the spines and a more sustained cell-wide elevation. The highfrequency transient elevation again depends on $\alpha 7$-containing receptors, whereas the sustained elevation can be triggered by other nicotinic receptors and depends on calcium release from internal stores and probably influx through voltage-gated L-type
\end{abstract}

calcium channels as well. Retrograde axonal stimulation of the neurons at high frequency mimics synaptic stimulation in producing sustained cell-wide calcium increases that depend on L-type channels and release from internal stores, but it does not produce calcium transients in the spines. Thus frequent action potentials are sufficient to generate the cell-wide increases, but $\alpha 7$ containing receptors are needed for spine-specific effects. Patchclamp recording indicates that $\alpha 7$-containing receptors preferentially desensitize at high-frequency stimulation, accounting for the inability of the stimulation to sustain high calcium levels in the spines. The spatial and temporal differences in the patterns of calcium elevation could enable the neurons to monitor their own firing histories for regulatory purposes.

Key words: nicotinic; spines; calcium; acetylcholine receptors; ciliary ganglion; $\alpha 7$
Dendritic spines have been the subject of intense study because they first were recognized as primary sites of synaptic excitation and likely sites of synaptic plasticity in the CNS (for review, see Harris, 1999). Their raison d'être appears to be an ability to segregate electrical and biochemical components of synaptic signaling such that the synaptic current can spread to other compartments whereas chemical effects are confined mainly to the spine of origin (Koch and Zador, 1993; Yuste and Denk, 1995). This has been demonstrated best for synaptically driven calcium elevations in hippocampal spines (Muller and Connor, 1991; Yuste and Denk, 1995; Svoboda et al., 1996), where the calcium transients mediate synaptic plasticity (for review, see Malenka and Nicoll, 1999). Constraining calcium elevations to individual spines serves a dual purpose: it permits limited calcium influx to achieve a high, local concentration for maximum regulatory impact on adjacent molecules, and it spatially confines the regulatory effects to one or a few nearby spines. The spatial constraint may be essential for maintaining the input specificity of synaptic plasticity (Koch and Zador, 1993; Yuste and Denk, 1995) and for reducing the risk of excitotoxicity (Choi, 1992).

Received July 12, 2000; revised Oct. 6, 2000; accepted Nov. 3, 2000.

This work was supported by National Institutes of Health Grants NS12601, NS35469, and RR04050 and by Tobacco-Related Disease Research Program Grant 9RT-0221. We thank Drs. Maryann Martone and Gary Fan (University of California, San Diego) for advice on sample preparation and image collection, and we thank Dr. Keith Brain (University of Sydney, Sydney, Australia) for advice on retrograde dye filling of neurons.

Correspondence should be addressed to Dr. Darwin K. Berg, Department of Biology 0357, University of California, San Diego, 9500 Gilman Drive, La Jolla, CA 92093-0357. Email: dberg@ucsd.edu.

Copyright $\odot 2001$ Society for Neuroscience $0270-6474 / 01 / 210771-11 \$ 15.00 / 0$
Most spines that have been analyzed to date receive glutamatergic input and depend on NMDA receptors for much of the calcium influx that has been observed. An interesting exception is that of somatic spines on chick ciliary ganglion neurons. Recent studies show that ciliary spines are heavily endowed with nicotinic acetylcholine receptors containing $\alpha 7$ subunits (Shoop et al., $1999)$. Such receptors ( $\alpha 7-n A C h R s)$ have a high relative calcium permeability, equivalent to that of NMDA receptors (Bertrand et al., 1993; Seguela et al., 1993), and generate large synaptic currents when activated (Zhang et al., 1996; Ullian et al., 1997). Surprisingly, $\alpha 7$-nAChRs are excluded from postsynaptic densities (Jacob and Berg, 1983), which instead contain a less abundant nAChR subtype having $\alpha 3$ and other subunits $\left(\alpha 3^{*}\right.$-nAChRs; Jacob et al., 1984; Vernallis et al., 1993). During development the $\alpha 7$-nAChRs are required for reliable, synchronized nicotinic transmission through the ganglion (Chang and Berg, 1999). The receptors remain in abundance throughout adulthood but become less important for acute ganglionic transmission at later times, when $\alpha 3^{*}$-nAChRs suffice (Chiappinelli, 1983; Chang and Berg, 1999) in combination with electrical synapses that form between preganglionic calyces and postganglionic ciliary neurons (Martin and Pilar, 1964a). The calcium permeability of $\alpha 7$ nAChRs, their abundance and positioning on somatic spines, and their apparent dispensability for acute transmission in adulthood suggest that the receptors play other signaling roles. A prime candidate would be regulation of calcium-dependent events in the postsynaptic cell. By translating firing history into specific temporal and spatial patterns of calcium elevation, the receptor could produce distinctive regulatory effects. We have used calcium imaging and rapid multi-photon laser-scanning fluorescence mi- 
croscopy to examine the contributions of $\alpha 7$-nAChRs to synaptically driven calcium transients in the postsynaptic cell and to assess how the resulting patterns reflect the frequency and duration of synaptic input to the neurons.

\section{MATERIALS AND METHODS}

Dye loading of ciliary ganglia. Ciliary ganglia were dissected with preganglionic and postganglionic nerve roots intact from embryonic day 15 (E15) chick embryos and from 3-week-old chickens, and each postganglionic nerve root was trimmed to a length of 2-4 $\mathrm{mm}$. Neurons in the ganglia were backloaded with the calcium fluorescent indicator dye Oregon green-1 conjugated to 10,000 MW dextran (Molecular Probes, Eugene, OR). The dye was chosen in part because of its relatively low affinity for calcium $\left(K_{\mathrm{D}}=398 \mathrm{nM}\right.$ [SCAP], as reported by Molecular Probes for the batch that was used) so that bound calcium could be expected to dissociate rapidly and not artificially prolong the calcium signal that is observed. The methods for dye loading have been described previously (Brain and Bennett, 1995) and were followed here with minor modifications. Briefly, a drawn out Pasteur pipette was used to apply a saturated solution of Oregon green-1-dextran to the postganglionic nerve root for $1.5-3 \mathrm{hr}$ at $37^{\circ} \mathrm{C}$. An oxygenated phosphate-free buffer containing (in $\mathrm{mM}$ ) $170 \mathrm{Na}^{+}, 5 \mathrm{~K}^{+}, 5 \mathrm{Ca}^{2+}, 2 \mathrm{Mg}^{2+}, 169 \mathrm{Cl}^{-}, 20 \mathrm{HCO}_{3}{ }^{-}$, and 11 glucose, $\mathrm{pH}$ 7.4, was used both to perfuse ganglia and to dissolve the dye. After backfilling, the ganglia were perfused for an additional $10 \mathrm{~min}$ and then mounted for stimulation and recording in the oxygenated buffer at $37^{\circ} \mathrm{C}$.

Calcium imaging. Visualization of the calcium dye was performed with a high-speed multi-photon laser-scanning microscope designed and built at the National Center for Microscopy and Imaging Resources Center at the University of California, San Diego (Fan et al., 1999). This system uses a femtosecond pulsed laser system (Spectra-Physics, Mountain View, CA) and is built around a highly modified version of the Nikon RCM 8000 video-rate confocal instrument (Tsien and Bacskai, 1995). The microscope system used in these studies was the development prototype for the Bio-Rad RTS2000 (Bio-Rad Laboratories, Hercules, CA). The instrument has the normal advantages of a typical multi-photon confocal microscope (e.g., decreased photo damage, greater depth of visualization) as well as the additional advantage of being able to capture images faster than video-rate. Most of the images that were recorded for this study were taken at $18.5 \mathrm{msec} / \mathrm{frame}$. To examine rapid rise times, we achieved a greater sampling frequency (2-8 $\mathrm{msec} /$ frame) by reducing the frame size or by using line scanning. Data were transferred directly from a real-time image- processing subsystem (Datacube) to a hard disk array developed specifically for this instrument by Nikon. These operations were managed by a user interface running under Windows NT. Some analysis of data was performed as data streamed from the preparation, allowing calcium fluctuations to be tracked during an experiment. Subsequent processing of the data was accomplished with the RCM software created specifically for this instrument. Subsequent analysis was performed with RCM software, NIH Image, and CricketGraph.

Ganglia were stimulated by using a suction electrode attached to either the preganglionic or postganglionic nerve root and a Master-8 (AMPI, Jerusalem, Israel) controller device to deliver trains of electrical pulses. Stimulation was triggered by the RCM software, allowing the visual data to be time-locked with the stimulus data. An individual stimulus within a train was typically $1 \mathrm{msec}$ in duration at $12-15 \mathrm{~V}$ (the minimal voltage required for robust stimulation was determined experimentally). Atropine at $100 \mathrm{~nm}$ (Calbiochem, La Jolla, CA) was included routinely in the bath solution during recording to prevent the activation of muscarinic receptors. When $\alpha 7-\mathrm{nAChRs}$ were to be blocked selectively, $\alpha$-bungarotoxin ( $\alpha$-Bgt; Molecular Probes) was added to a final concentration of $100 \mathrm{nM}$ at least $30 \mathrm{~min}$ before stimulation of the ganglion. When $\alpha 7-n A C h R s$ were to be imaged as part of the experiment, fluorescently conjugated $\alpha$-Bgt (rhodamine- $\alpha$-Bgt; Molecular Probes) was applied at $100 \mathrm{nM}$ to the ganglion, and images were collected after 10-15 min at $37^{\circ} \mathrm{C}$. When calcium release from internal stores was to be blocked, ganglia were incubated with either $10 \mu \mathrm{M}$ ryanodine or $1 \mu \mathrm{M}$ thapsigargin (Calbiochem) for $>30 \mathrm{~min}$ before stimulation. Nifedipine at $10 \mu \mathrm{M}$ (Calbiochem) was used to block L-type voltage-gated calcium channels. When ganglia were stimulated via the postganglionic nerve root, $20 \mu \mathrm{M}$ D-tubocurarine (Calbiochem) was included in the bath to prevent any intraganglionic nicotinic signaling.

Ganglia could be imaged continuously for $\sim 22 \mathrm{sec}$ at $18.5 \mathrm{msec} / \mathrm{frame}$ ( $>1100$ frames) before significant photobleaching occurred. Neurons were excluded from the data set if they underwent bleaching or if their calcium levels did not return to baseline after stimulation. When calcium levels were to be compared quantitatively in different regions of the same cell, the mean fluorescence intensity was measured for defined circles with diameters of $2.5 \mu \mathrm{m}$ positioned on the neuron perimeter. Circles were chosen either to include ("on-spine") or to exclude ("off-spine") membrane regions later shown to be rich in $\alpha$-Bgt binding sites, indicative of $\alpha 7$-nAChR clusters correlated with spine mats (Shoop et al., 1999, 2000). Calcium levels were compared for the same neuron over space, time, or incubation condition, but only relative rather than absolute levels were compared among neurons because of variations in extent of dye loading and fluorescence yield. For each set of experiments the gain of the photomultiplier was adjusted to ensure operation in the midrange. The time course of decay for the calcium signal was fit to either a first- or second-order exponential with the Origin software (Microcal Software, Northampton, MA). The best fit was determined by performing an $F$ test of significance.

Imaging on dissociated neurons. Voltage-gated calcium channels and $\alpha 7$-nAChRs were colabeled on freshly dissociated E15 ciliary ganglion neurons by incubating Alexa-488 conjugated $\alpha$-Bgt (Molecular Probes) for $45 \mathrm{~min}$ immediately after the neurons were dissociated and plated in culture medium as previously described (Shoop et al., 2000). After three 5 min rinses in culture medium, the neurons were fixed in $4 \%$ paraformaldehyde in phosphate buffer for $30 \mathrm{~min}$ at room temperature, rinsed five times in PBS $\left(0.15 \mathrm{M} \mathrm{NaCl}\right.$ and $\left.0.01 \mathrm{M} \mathrm{Na}_{2} \mathrm{HPO}_{4}, \mathrm{pH} 7.4\right)$, and permeabilized in PBS containing $0.1 \%(\mathrm{v} / \mathrm{v})$ Triton X-100; they were incubated for 3 $\mathrm{hr}$ at room temperature in PBS with 5\% normal donkey serum containing a 1:200 dilution of a rabbit antibody directed against the $\alpha_{1 \mathrm{c}}$ subunit of L-type voltage-gated calcium channels (Chemicon, Temecula, CA) or rabbit IgG as a negative control. After five rinses in PBS the neurons were incubated for $1 \mathrm{hr}$ in the secondary antibody, Cy3-conjugated anti-rabbit (1:200 dilution; Jackson ImmunoResearch Laboratories, West Grove, PA), in PBS with $5 \%$ normal donkey serum and $0.1 \%$ Triton X-100.

Labeled cells were viewed with a Bio-Rad MC1024 confocal microscope with a $63 \times, 1.4$ numerical aperture objective lens. Optical sections were taken at $0.75 \mu \mathrm{m}$ intervals through the neuron, and the final volume was assembled digitally with Lasersharp software (Bio-Rad). A final projection was reconstructed from this volume with NIH Image software (National Institutes of Health, Bethesda, MD).

Electrophysiology. Synaptic currents and postsynaptic action potentials were recorded from neurons in dissected E15 whole ciliary ganglia with patch-clamp techniques as previously described (Chang and Berg, 1999). Briefly, E15 ciliary ganglia were excised with the preganglionic nerve root attached and then trimmed and treated with enzymes to loosen connective tissue. A suction electrode was used to stimulate the preganglionic nerve root while whole-cell patch-clamp recording was used from individual neurons in situ at $37^{\circ} \mathrm{C}$ to record either the resulting synaptic current in voltage-clamp mode or the resting membrane potential and elicited postganglionic action potentials in current-clamp mode. Cells were discarded if the resting potential at the end of the recording session was more positive than $-50 \mathrm{mV}$ or if the cell failed to follow presynaptic stimulation consistently with postsynaptic action potentials during the first $5 \mathrm{sec}$ stimulation period at $1 \mathrm{~Hz}$. The extracellular perfusion solution (recording medium) contained (in $\mathrm{mM}$ ): $120 \mathrm{NaCl}, 4 \mathrm{KCl}, 10$ glucose, $2 \mathrm{CaCl}_{2}, 1 \mathrm{MgSO}_{4}, 30 \mathrm{NaHCO}_{3}$, and $1 \mathrm{NaH}_{2} \mathrm{PO}_{4}, \mathrm{pH}$ 7.4. Atropine $(100 \mathrm{nM})$ was added routinely, and the solution was warmed to $37^{\circ} \mathrm{C}$ and gassed with $95 \% \mathrm{O}_{2} / 5 \% \mathrm{CO}_{2}$. The intracellular solution (in the patch pipette) contained (in $\mathrm{mM}$ ): $140 \mathrm{KCl}, 5$ glucose, 2 EGTA-KOH, 1 $\mathrm{MgCl}_{2}$, and $10 \mathrm{HEPES}$, pH 7.2. Other aspects were as described previously (Chang and Berg, 1999).

The relative declines in $\alpha 7-\mathrm{nAChR}$ and $\alpha 3^{*}-\mathrm{nAChR}$ responses during a stimulus train were calculated on the basis of the following. Normally $90 \%$ of the peak synaptic current is generated by $\alpha 7-\mathrm{nAChRs}$, in the absence of previous desensitization (Zhang et al., 1996; Liu and Berg, 1999b). At later times the $\alpha 3^{*}$-nAChR response dominates. Accordingly, measurement of synaptic current $7.5 \mathrm{msec}$ after the peak response was used to determine the decline in the $\alpha 3^{*}$-nAChR response as a function of stimulus number, because the $\alpha 7-\mathrm{nAChR}$ response had declined to $<$ $3 \%$ of its original value by then and the $\alpha 3^{*}$-nAChR response was still large enough to measure accurately. Curve fitting for each individual trial to distinguish $\alpha 3^{*}$ - and $\alpha 7$-nAChR components as done previously (Zhang et al., 1996) was impractical here because of the small amplitude of the signals toward the end of the stimulus train. Once the relative decline in $\alpha 3^{*}$-nAChR response as a function of stimulus number was known, the information was used to calculate how the $\alpha 3^{*}$-nAChR portion of the peak current would have changed with stimulus number; this, in turn, was used to determine (by subtraction) the amplitude of the 


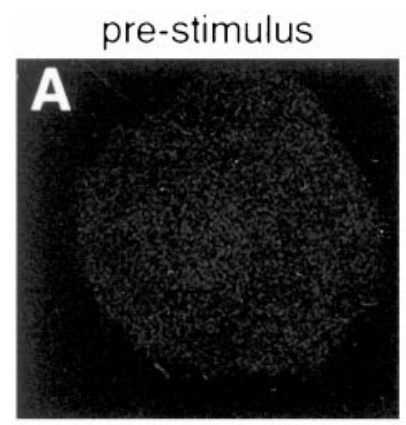

during stimulation
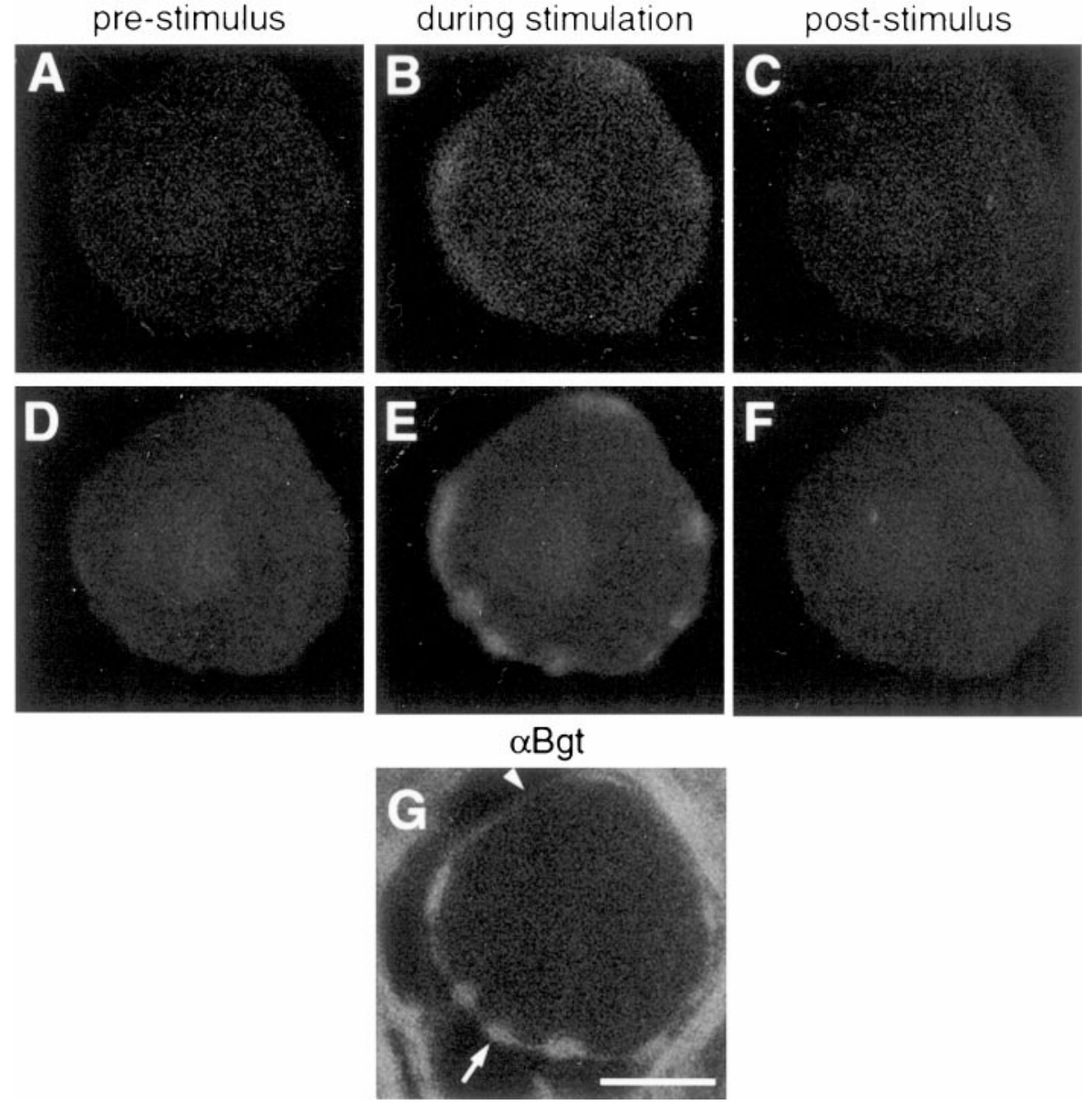

$\alpha 7$-nAChR component of the peak as a function of stimulus number. In this way both the $\alpha 3^{*}$-nAChR and $\alpha 7$-nAChR components of the synaptic response were calculated for each stimulus and then expressed as a fraction of their respective values seen at the outset (i.e., generated by the first stimulus in the train) for normalization.

In some cases whole-cell patch-clamp recording was used to measure the nicotinic responses of freshly dissociated E14-E15 ciliary ganglion neurons before and after exposure to individual drugs. In these cases the techniques and procedures were as previously described (Liu and Berg, 1999a,b).

Materials. White leghorn chick embryos were obtained from McIntyre Poultry (Lakeside, CA) and maintained at $37^{\circ} \mathrm{C}$ in a humidified incubator. Three-week-old chickens were purchased from the same source and killed on the day of arrival for experiments. All animal care and handling was in strict accordance with the policies of the University of California, San Diego, Committee on Animal Subjects and the American Association for Accreditation of Laboratory Animal Care. The University holds a currently approved National Institutes of Health Assurance and a United States Department of Agriculture License. Reagents were purchased from Sigma (St. Louis, MO) unless otherwise indicated.

\section{RESULTS}

\section{Low-frequency synaptic stimulation induces calcium transients confined to spines}

Rapid calcium imaging was used to examine the effects of synaptic stimulation in situ on intracellular calcium levels of chick ciliary ganglion neurons. Ganglia were dissected from E15 embryos and backfilled via the postganglionic nerve root with the calcium indicator fluor Oregon green-1 conjugated to dextran. After rinsing, the ganglia were stimulated synaptically with a suction electrode positioned on the preganglionic nerve root. Individual fluorescence images were collected at a rapid rate $(18.5 \mathrm{msec} /$ frame $)$ with a modified laser-scanning microscope, allowing for the visualization
Figure 1. Fluorescence imaging of calcium transients induced in spine regions by low-frequency synaptic stimulation. Neurons in dissected E15 ciliary ganglia were filled with Oregon green-1dextran via the postganglionic nerve root and then imaged with a multi-photon laser-scanning microscope at $18.5 \mathrm{msec} /$ frame before, during, and after synaptic stimulation through the preganglionic nerve root. $A-C$, Single frames of a neuron taken $20 \mathrm{msec}$ before, immediately after, and $1 \mathrm{sec}$ after delivering a single synaptic stimulus. $D-F$, Averaged images of eight successive responses to $1 \mathrm{~Hz}$ stimulation taken $20 \mathrm{msec}$ before, immediately after, and $800 \mathrm{msec}$ after each stimulus. $G$, Labeling with rhodamineconjugated $\alpha$-Bgt for $10 \mathrm{~min}$ at the end of the experiment to identify $\alpha 7$-nAChR clusters defining spine mats. The same neuron is shown throughout. A single stimulus produces calcium transients in discrete regions along the perimeter. Averaging the responses intensifies the signal and shows that the calcium transients consistently correlate in location with spine mats defined by $\alpha 7$-nAChR clusters. A total of 20 neurons was examined in this manner and gave similar results. Arrow, A spine mat (on-spine); arrowhead, a region lacking detectable spines (off-spine). Scale bar, $10 \mu \mathrm{m}$. of calcium entry into a single optical cross section of an entire neuron. Relatively large neurons were chosen for the imaging and, therefore, were likely to be ciliary instead of choroid neurons (McNerney et al., 2000). Background fluorescence, defined as the signal $20 \mathrm{msec}$ before stimulation, was low in the neurons (Fig. 1A). A single stimulus caused a detectable rise in the calcium levels within the first $18.5 \mathrm{msec}$ after stimulation, and it was confined to regions immediately underlying the cell membrane at specific sites (Fig. 1B). Within $1 \mathrm{sec}$ after stimulation the calcium levels had returned to baseline (Fig. 1C). When stimulated with a train of stimuli at $1 \mathrm{~Hz}$, the pattern reproduced. Eight successive trials were averaged to show more clearly the baseline levels before stimulation (Fig. $1 D$ ), during the first $18.5 \mathrm{msec}$ after stimulation (Fig. $1 E$ ), and after the calcium level returned to baseline (Fig. $1 F$ ). The images indicate that the $1 \mathrm{~Hz}$ train of stimuli caused localized, transient increases in the concentration of free calcium immediately beneath certain regions of the plasma membrane.

The nature of the regions displaying the transient calcium increases was examined by labeling the neurons with rhodamine$\alpha$-Bgt after the calcium imaging had been completed. The rhodamine- $\alpha$-Bgt binds to $\alpha 7$-nAChRs, which are concentrated on somatic spines folded into distinct mats on ciliary neurons (Shoop et al., 1999). As a result, the large clusters of fluorescent $\alpha$-Bgt labeling on the cell surface indicate the location of spine mats. Because the receptors are concentrated and bind $\alpha$-Bgt with high affinity (Couturier et al., 1990; Schoepfer et al., 1990), they can be detected in the ganglion with confocal microscopy under these conditions without having to rinse away unbound toxin and risk 
A

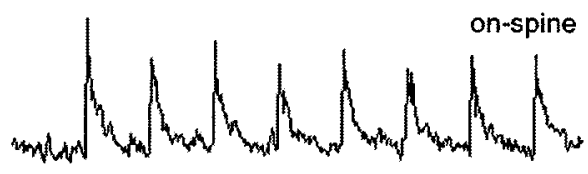

B

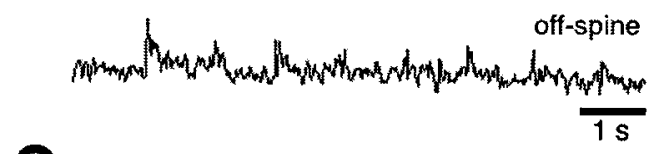

C

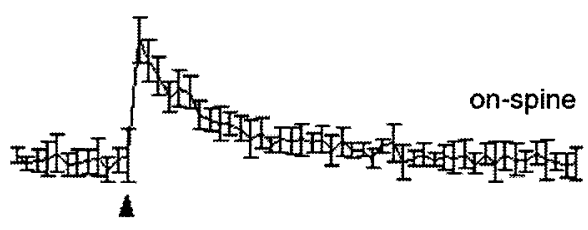

D

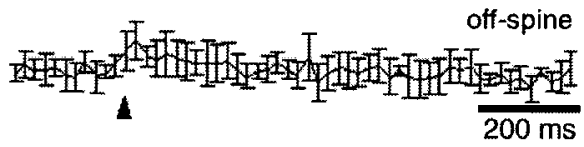

Figure 2. Time courses of synaptically driven calcium transients at identified sites on the postsynaptic neuron. The amount of calcium fluorescence in a 2.5- $\mu \mathrm{m}$-diameter circle either overlying a spine mat (on-spine) or overlying part of the cell surface devoid of spines (off-spine) was quantified from a series of images collected continuously during synaptic stimulation at $1 \mathrm{~Hz}(18.5 \mathrm{msec} / \mathrm{image})$. The cell that was analyzed was the same as that in Figure 1, and the on-spine and off-spine regions that were measured were those indicated by the arrow and arrowhead, respectively, in Figure $1 G$. $A$, Continuous imaging on-spine. $B$, Continuous imaging off-spine. $C$, Eight averaged responses from $A$. Error bars are shown for each individual time point. The arrowheads indicate the time of stimulation. $D$, Eight averaged responses from $B$ with the corresponding error bars. Synaptic stimulation at $1 \mathrm{~Hz}$ elicits calcium transients that reach maximum during the first $18.5 \mathrm{msec}$ poststimulation and quickly return to baseline; they are confined mainly to the spine mat area because very little change is seen in the off-spine region. Similar results were obtained with 18 neurons that were tested. Calibration: $A, B, 1 \mathrm{sec}, C, D, 200 \mathrm{msec}$.

moving the preparation. It was clear that the somatic spine mats, defined by rhodamine- $\alpha$-Bgt binding to $\alpha 7$-nAChRs, exactly coincided with the regions displaying the calcium transients (Fig. 1G).

The time course of the calcium transients in discrete regions was examined in more detail by quantifying the fluorescence in a 2.5- $\mu$ m-diameter circle either overlying a spine mat ("on-spine") or overlying an equivalent portion of the surface membrane lacking detectable $\alpha 7$-nAChR labeling ("off-spine"). In such experiments, continuous imaging of the calcium signal was performed during the $1 \mathrm{~Hz}$ train of synaptic stimulation as above, and then the cells were labeled with rhodamine- $\alpha$-Bgt to define the spine mats and permit selection of appropriate on-spine (e.g., Fig. 1G, arrow) and off-spine (e.g., Fig. $1 G$, arrowhead) regions of the images for analysis. Examined in this manner, on-spine regions showed rapid increases in calcium after each stimulus of the $1 \mathrm{~Hz}$ train (Fig. 2A). The increases reached a maximum within the first $18.5 \mathrm{msec}$ (first frame) and declined over the next several frames to reach baseline in $<1 \mathrm{sec}$. Very little increase in calcium could be detected in the off-spine region (Fig. $2 B$ ) or in the cytoplasm away from the plasma membrane (data not shown). Thus the calcium transients consistently occurred on-spine, and, although the amplitude of the transients at a given on-spine location varied from stimulus to stimulus, there seemed to be no failures. If an on-spine region responded to one stimulus in the train (as most did), it responded to all stimuli in the train.

For greater clarity, all eight responses elicited by an 8-sec-long $1 \mathrm{~Hz}$ train of stimuli were averaged both for on-spine (Fig. 2C) and off-spine (Fig. 2D) regions. A significant, rapidly rising and rapidly decaying calcium elevation is apparent in the on-spine region, whereas only a small, slowly decaying elevation can be distinguished in the off-spine region. As indicated by the figure, all of the rise on-spine occurred during the first $18.5 \mathrm{msec}$, represented by the time between the stimulus and the peak response. In fact, reducing the area of the circle that was examined so that the image could be collected as rapidly as $8 \mathrm{msec}$ after the stimulus still yielded a peak on-spine response, indicating that it occurred very quickly. The mean time constant of decay for the calcium transient on-spine was $163 \pm 25 \mathrm{msec}(n=18$ cells $)$.

\section{High-frequency synaptic stimulation induces calcium elevations throughout the soma}

High-frequency stimulation produces a qualitatively different pattern from that seen with $1 \mathrm{~Hz}$. A $5 \mathrm{sec}$ stimulation at $50 \mathrm{~Hz}$ produces a sustained calcium elevation extending across the entire cell; the elevation quickly collapses to baseline after stimulation ceases (Fig. $3 A-C$ ). The pattern depended on the frequency of stimulation rather than on the number of stimuli delivered because even after three stimuli at $50 \mathrm{~Hz}$ the cell-wide increase was seen, although eight stimuli at $1 \mathrm{~Hz}$ failed to produce it. Comparing the time courses of calcium changes in on-spine and off-spine regions shows a complex pattern. At $50 \mathrm{~Hz}$ on-spine the calcium level quickly rises to a maximum and decays slowly in a biphasic manner throughout the $5 \mathrm{sec}$ stimulation period (Fig. $3 D)$. Off-spine the calcium level rises to a smaller maximum and decays slowly in a monophasic manner (Fig. $3 E$ ). Analyzing the responses from a number of cells yielded mean time constants for decay on-spine of $3.3 \pm 1.4 \mathrm{sec}($ mean $\pm \mathrm{SEM} ; n=16)$ and $15 \pm$ 4 min $(n=16)$. The latter should be considered only an estimate because it extends so far beyond the $5 \mathrm{sec}$ stimulation period that was examined. The faster decaying component represented $37 \pm$ $6 \%(n=16)$ of the maximum response. Analysis of off-spine regions yielded an estimated mean single time constant for decay of $18 \pm 3 \min (n=16)$, a value similar to that found for the slowly decaying component on-spine. At the end of the $50 \mathrm{~Hz}$ stimulation the calcium elevation collapsed to baseline, with time constants of $380 \pm 200$ and $560 \pm 260 \mathrm{msec}(n=16)$ for on- and off-spine locations, respectively.

A better estimate for the slowly decaying component during 50 $\mathrm{Hz}$ stimulation was obtained by extending the stimulation period to $30 \mathrm{~min}$. Imaging the neurons briefly at widely spaced intervals to avoid bleaching allowed a mean time constant of decay to be calculated for the entire period (Fig. $3 F$ ). The value obtained, $17 \pm$ 5 min $(n=4)$ for the slow on-spine component, is in good agreement with that extrapolated from the $5 \mathrm{sec}$ stimulation period above. After a brief rest period $50 \mathrm{~Hz}$ stimulation of the same neuron again produced the original pattern of calcium elevation, indicating it had not been damaged by the procedure (Fig. 3G). Stimulation at $20 \mathrm{~Hz}$ produced on- and off-spine calcium elevations qualitatively similar in time courses to those seen at $50 \mathrm{~Hz}$ (data not shown). Taken together, the results indicate that both the spatial and temporal patterns of calcium elevation caused by highfrequency synaptic stimulation are quite different from those caused by low-frequency stimulation in the same neurons. 

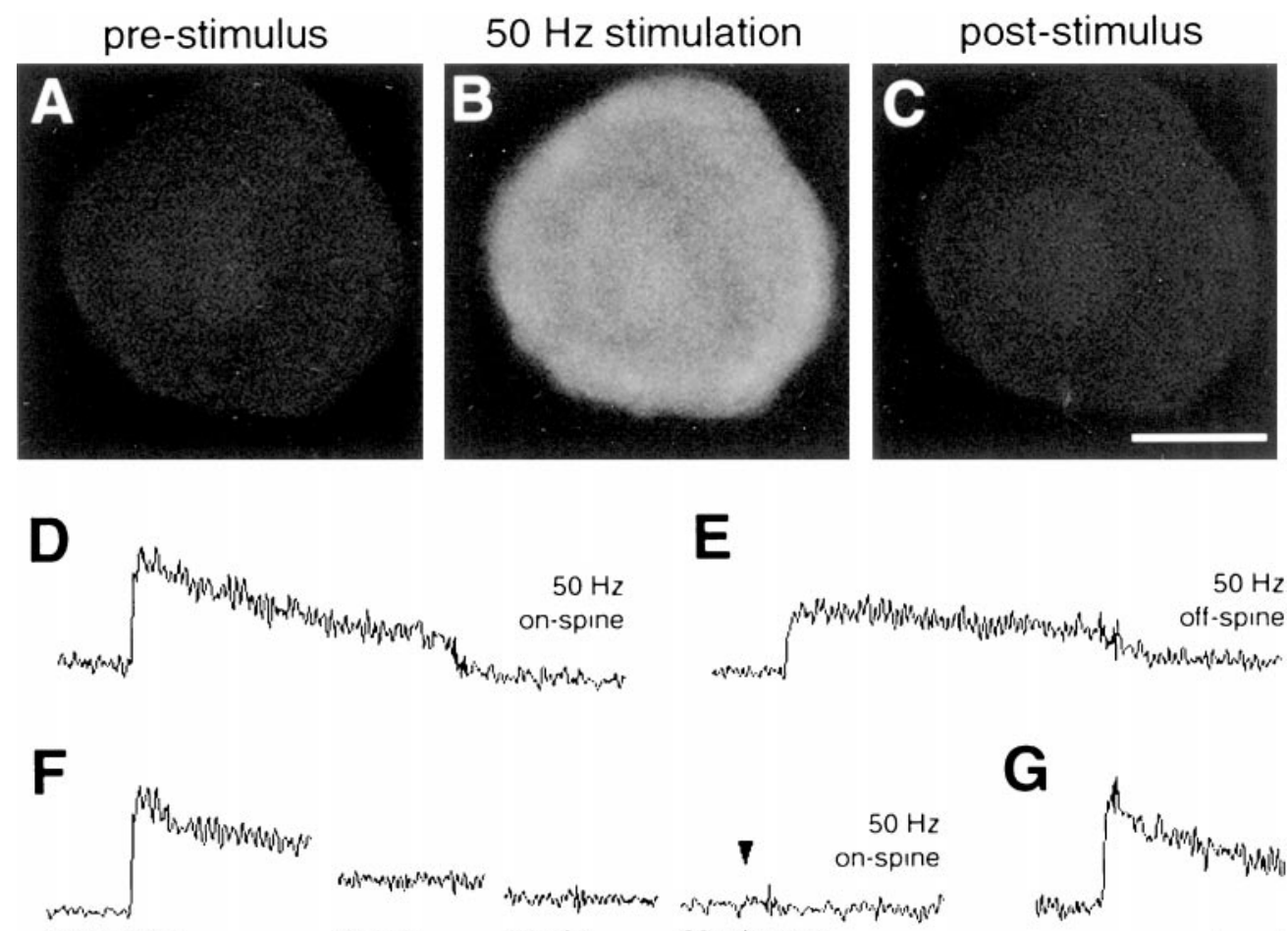

$50 \mathrm{~Hz}$ start

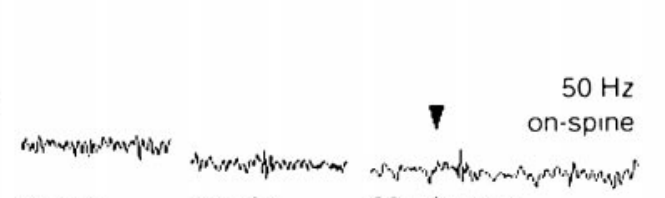

$10 \mathrm{~min} \quad 20 \mathrm{~min}$

30 min stop

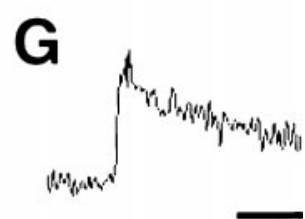

Figure 3. Cell-wide spread of calcium elevations at high-frequency synaptic stimulation. The same cell shown in Figure 1 was stimulated synaptically at $50 \mathrm{~Hz}$ and analyzed as described in Figure 2. $A-C$, Images collected $20 \mathrm{msec}$ before, midway through a $5 \mathrm{sec}$ stimulation at $50 \mathrm{~Hz}$, and $1 \mathrm{sec}$ after the stimulation was stopped. $D$, $E$, Continuous quantification of calcium fluorescence in the on-spine and off-spine regions identified in Figure $1 G$ while the neuron was stimulated synaptically at 50 $\mathrm{Hz}$. High-frequency stimulation causes a rapid increase in calcium fluorescence both on- and off-spine; the decay is biphasic with both a fast and slow component on-spine, whereas it is monophasic with only a slow component off-spine. Similar results were obtained with 16 neurons that were tested. $F$, Stimulation of a neuron continuously for $30 \mathrm{~min}$ at $50 \mathrm{~Hz}$ but imaged only briefly on-spine at 10 min intervals, as indicated. Arrowhead, Termination of the stimulation. A smooth, slow decline in the calcium elevation occurs over the 30 min stimulation period. $G$, Same neuron as in $F$, allowed a brief recovery before being stimulated again at 50 $\mathrm{Hz}$ to show that the cell remained competent. Scale bar for $A-C, 10 \mu \mathrm{m}$; calibration for $D-G, 1 \mathrm{sec}$.

\section{Calcium transients in spines depend on $\alpha 7-n A C h R s$}

Because $\alpha 7$-nAChRs are the major nicotinic receptor on ciliary ganglion neurons and because the receptors are concentrated on the spines and have a high relative permeability to calcium, it seemed likely that they would play a major role in the calcium transients elicited by synaptic stimulation. This was tested by comparing the calcium transients induced by stimulation in the same neurons before and after treatment with $100 \mathrm{~nm} \alpha$-Bgt for 30 min to block $\alpha 7-n A C h R s$. Under these conditions the synaptic currents generated by $\alpha 3^{*}$-nAChRs are sufficient to elicit postsynaptic action potentials approximately one-half of the time, averaged over the ciliary population (Chang and Berg, 1999). At $1 \mathrm{~Hz}$ the toxin treatment almost completely blocked calcium transients in the on-spine regions seen by signal averaging (Fig. $4 A, B$ ). The residual calcium transient seen in the presence of the toxin was comparable with that seen for off-spine regions (Fig. 4C). The off-spine signal was not reduced by $\alpha$-Bgt (Fig. 4D).

At $50 \mathrm{~Hz}$ stimulation the toxin blockade affected only the initial component of the calcium elevation on-spine. The maximum response was reduced and the decay phase was monophasic (Fig. $4 F, G)$, resembling that seen above for off-spine calcium elevations induced by $50 \mathrm{~Hz}$ stimulation. Control experiments showed that no change of signal occurred in on-spine regions during the test period when toxin was omitted from the incubation (Fig. $4 H, I)$. Calculating the proportion of the peak on-spine signal that remained after $\alpha$-Bgt treatment yielded a value of $65 \pm 8 \%(n=$ 14 cells), in good agreement with that found above for the portion of the response that slowly decays at $50 \mathrm{~Hz}$ stimulation. Including $20 \mu \mathrm{M}$ D-tubocurarine in the bath to block all nAChRs completely eliminated the calcium transients induced by either 1 or $50 \mathrm{~Hz}$ (Fig. $4 E, J$ ). The toxin results demonstrate that $\alpha 7$-nAChRs are essential for the transient calcium increases elicited by $1 \mathrm{~Hz}$ synaptic stimulation in spines but contribute less significantly to the extended increases seen at $50 \mathrm{~Hz}$ throughout the cell. These latter cell-wide increases seen at high-frequency stimulation ap- parently can be triggered by synaptic activation of $\alpha 3^{*}$-nAChRs because they persist after toxin blockade. Similarly, the small, transient increases seen in off-spine regions at low-frequency stimulation also arise from activation of $\alpha 3^{*}$-nAChRs.

Analysis of ganglia from older animals yielded the same kind of results that were obtained with E15 ganglia. Thus ciliary neurons in ganglia from 3-week-old chickens showed the rapid calcium transients confined to on-spine regions at $1 \mathrm{~Hz}$, and the transients were blocked almost completely by $\alpha$-Bgt (Fig. $5 A-C$ ), as was the case for neurons in E15 ganglia. Synaptic stimulation at $50 \mathrm{~Hz}$ produced sustained calcium elevation throughout the cell; onspine the elevation decayed in a biphasic manner, and blockade with $\alpha$-Bgt removed the more rapidly decaying component (Fig. $5 D, E)$ as it did for calcium elevations in E15 neurons synaptically driven at $50 \mathrm{~Hz}$. The calcium patterns that were observed, then, are not confined to early developmental stages in the ganglion but rather can be seen at posthatch times when the visual system and attendant reflexes are fully functional.

\section{Frequency-dependent attenuation of synaptic current limits $\alpha 7-n A C h R$ contributions}

The fact that $\alpha 7$-nAChRs rapidly desensitize in situ suggests an explanation for the short-lived calcium elevations that are $\alpha$-Bgtsensitive on-spine: the $\alpha 7$-nAChRs quickly may cease to contribute significantly at high-frequency stimulation. This was examined by using patch-clamp recording from neurons in situ to compare the stimulus-dependent attenuation of synaptic currents in response to low- and high-frequency stimulation of the presynaptic nerve root. At $1 \mathrm{~Hz}$ the peak whole-cell response showed no significant decline during the $5 \mathrm{sec}$ stimulation period (Fig. 6A). In contrast, at $50 \mathrm{~Hz}$ there was a rapid and large decrement in the whole-cell peak current. When the portion of the peak response attributable to $\alpha 7$-nAChRs was calculated (normally $\geq 90 \%$; Liu and Berg, 1999b), it was found to decline to approximately onethird within $1 \mathrm{sec}$ (Fig. 6B). Although the $\alpha 3^{*}$-nAChR response 


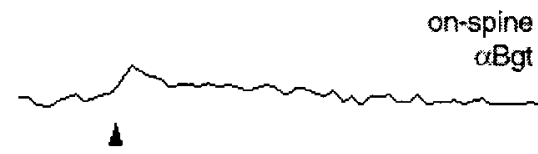

Figure 4. Effects of $\alpha 7$-nAChR blockade on synaptically driven calcium transients. Neurons were tested for calcium elevations during synaptic stimulation both before and after a $30 \mathrm{~min}$ exposure to $100 \mathrm{nM} \alpha$-Bgt to block $\alpha 7$-nAChRs; the results were analyzed as in Figures 2 and 3. $A-D$, Averaged sequential responses to eight stimuli at $1 \mathrm{~Hz}$ obtained from a single neuron either on-spine or off-spine before and after $\alpha$-Bgt treatment, as indicated. Note that the error bars (see Fig. 2) have been omitted both here and in subsequent figures for clarity, but the time from stimulus to peak response nonetheless represents the average of the first $18.5 \mathrm{msec}$ frame captured in each trial. $E$, Complete blockade of the calcium transient by $20 \mu \mathrm{M}$ D-tubocurarine. Arrowheads indicate the time of stimulation. F, $G$, Unaveraged responses elicited from a single neuron on-spine before and after $\alpha$-Bgt treatment while it was stimulated at $50 \mathrm{~Hz} . \mathrm{H}, \mathrm{I}$, Control showing no change in the amplitude or time course of the calcium transient elicited by 50 $\mathrm{Hz}$ stimulation when a cell was held for $30 \mathrm{~min}$ without $\alpha$-Bgt. Blockade of $\alpha 7$-nAChRs almost completely eliminated both the rapid on-spine calcium transient seen at $1 \mathrm{~Hz}$ and the rapidly decaying on-spine transient seen at $50 \mathrm{~Hz}$, reducing them to the kind of signal seen at off-spine regions. Similar results were obtained with 14 neurons that were tested. $J$, Complete blockade of the calcium elevation elicited by $50 \mathrm{~Hz}$ synaptic stimulation in the presence of $20 \mu \mathrm{M}$ D-tubocurarine. Calibration: $A-E, 200 \mathrm{msec} ; F-J, 1$ sec.

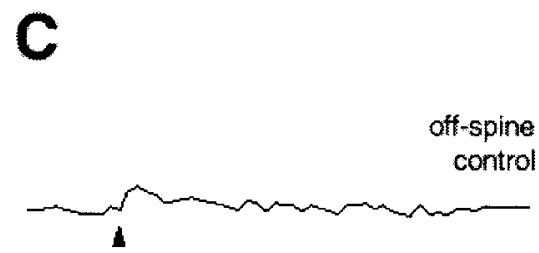

D

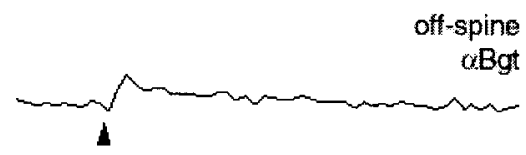

$\mathbf{E}$

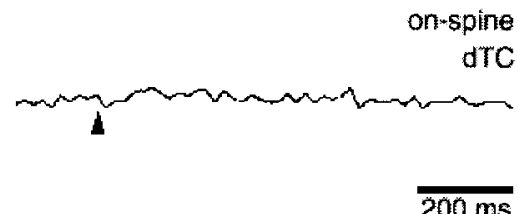

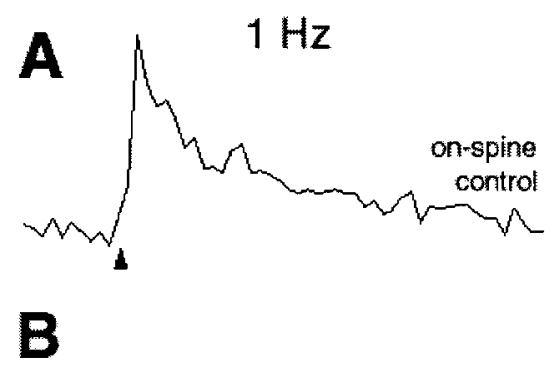
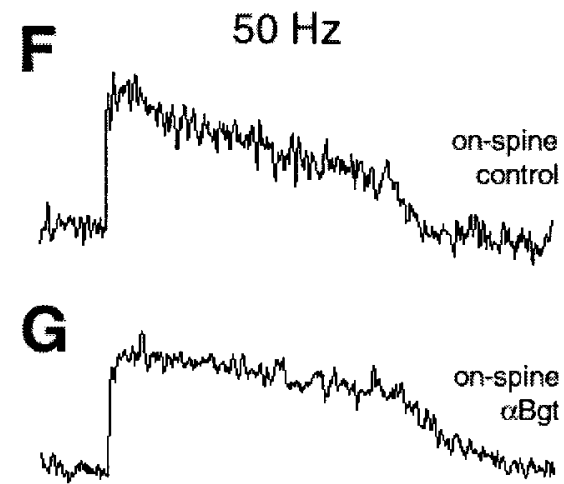

H

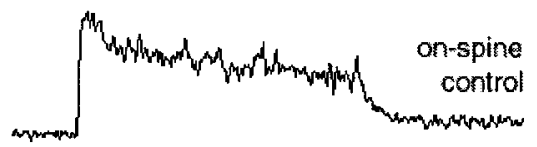

on-spine

dTC

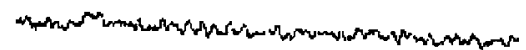

$1 \mathrm{~s}$ also declines, possibly because of reduced transmitter release (Fig. 6C), the decline was not as severe as that for $\alpha 7-n A C h R s$.

Despite the reduction in synaptic currents at high-frequency stimulation, the synapses were still capable of triggering action potentials with some frequency. At $1 \mathrm{~Hz}$, transmission was $100 \%$ reliable during the $5 \mathrm{sec}$ test period as seen by the five action potentials (Fig. 6D), whereas at $50 \mathrm{~Hz}$ it was much reduced but not eliminated (Fig. 6E). Some neurons showed no failure in transmission for the first 10 stimuli at high frequency (Chang and Berg, 1999), but all showed substantial failures at later times. Examining six neurons yielded an average number of $75 \pm 18$ (mean \pm SEM) for the number of action potentials elicited by the 250 stimuli delivered at $50 \mathrm{~Hz}$ for $5 \mathrm{sec} ; 13 \pm 6$ action potentials occurred during the final $2 \mathrm{sec}$ of stimulation. The fact that at least some action potentials occurred in all cells throughout the test period raises the possibility that voltage-gated channels may contribute importantly to the cell-wide calcium signal seen at high-frequency stimulation.

\section{Sustained calcium increases depend on multiple calcium sources}

Two potential sources of calcium, in addition to nAChRs, are voltage-gated calcium channels and release from internal stores.
Both are known to contribute to calcium levels in the neurons (Rathouz et al., 1996; Brain and Bennett, 1998). L-type calcium channels are distributed all over the cell body, as revealed by immunostaining with a monoclonal antibody directed against the $\alpha_{1 \mathrm{c}}$ subunit; no preferential localization is seen on spine mats defined by staining for $\alpha 7$-nAChRs (Fig. $7 A-C$ ). Blockade of L-type channels with $10 \mu \mathrm{M}$ nifedipine had no obvious effect on calcium transients that were induced by $1 \mathrm{~Hz}$ synaptic stimulation (Fig. 7D,E), but it did have a dramatic impact on calcium elevations in response to $50 \mathrm{~Hz}$. On-spine the elevations were reduced to baseline shortly after the initial maximum seen at $50 \mathrm{~Hz}$ (Fig. $7 F, G)$. The slowly decaying component was lost completely, and the residual response had a mean time constant for decay of $1.2 \pm$ $0.1 \mathrm{sec}(n=9)$. The amplitude of the residual response was $41 \pm$ $5 \%(n=9)$ of the peak response before nifedipine treatment. Thus both the relative amplitude and the time course of decay for the residual component approximated those calculated above for the on-spine calcium transient generated by $\alpha 7-n A C h R s$ at $50 \mathrm{~Hz}$, although the small difference in decay constants suggested some contribution of L-type channels to the on-spine signal. The much more important role of L-type channels in the sustained calcium signal can be seen readily in off-spine regions; in these cases the 

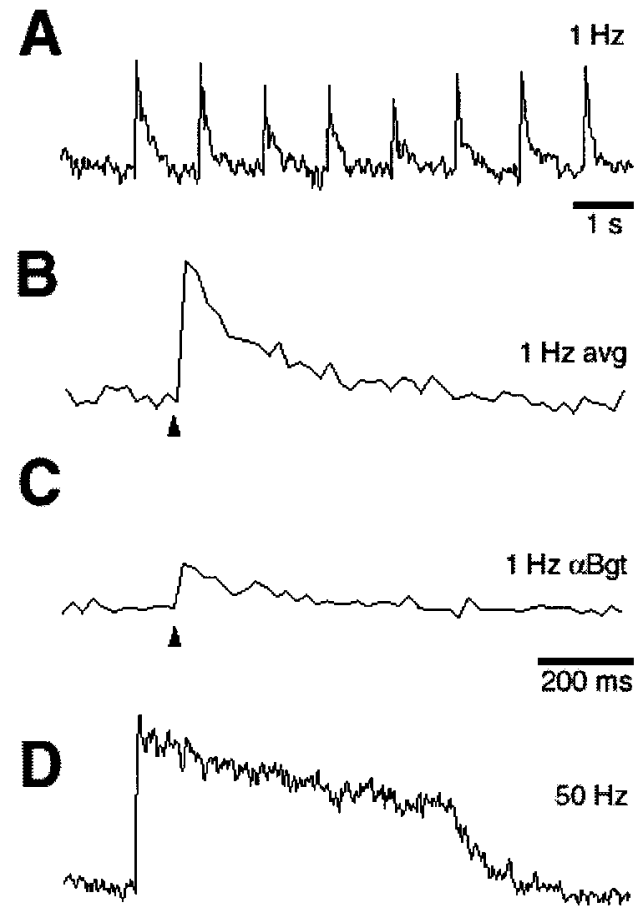

im

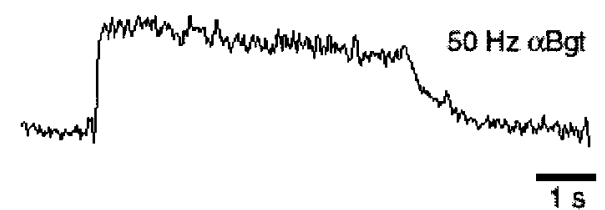

Figure 5. Synaptically driven calcium transients in ciliary neurons from posthatch chicks. Ciliary ganglia from 3-week-old chicks were dissected, loaded with dye, stimulated, and imaged as described for E15 ganglia in Figures 1-4. $A-C$, On-spine calcium transients elicited by $1 \mathrm{~Hz}$ synaptic stimulation and shown either as a continuous trace or as a signal averaged over eight responses either before or after a $30 \mathrm{~min}$ exposure to $\alpha$-Bgt to block $\alpha 7$-nAChRs, as indicated. $D, E$, On-spine calcium elevations induced by $50 \mathrm{~Hz}$ synaptic stimulation before and after $\alpha$-Bgt treatment. As in E15 ganglia, synaptic stimulation at $1 \mathrm{~Hz}$ induced rapid calcium transients on-spine, and the transients were almost completely dependent on $\alpha 7$-nAChRs; $50 \mathrm{~Hz}$ stimulation induced a sustained elevation showing a biphasic decay, and $\alpha 7-\mathrm{nAChR}$ blockade eliminated the rapidly decaying component. Similar results were obtained with all six ganglia that were tested (one neuron per ganglion). Calibration: $A, D, E, 1 \mathrm{sec} ; B, C, 200$ msec. Arrowheads indicate the time of stimulation.

$50 \mathrm{~Hz}$ signal was blocked almost completely by the nifedipine treatment (Fig. 7H,I).

Calcium release from internal stores also was tested for a contribution to the sustained cell-wide elevation induced by highfrequency synaptic stimulation. A $30 \mathrm{~min}$ incubation with $10 \mu \mathrm{M}$ ryanodine to block release from internal stores reduced the slowly decaying component of the on-spine calcium elevation caused by 50 $\mathrm{Hz}$ stimulation while having little, if any, effect on the more rapidly decaying component (Fig. 8A,B). Off-spine the ryanodine again decreased the amplitude of the slowly decaying calcium component (Fig. 8C,D). No significant effect of ryanodine treatment was seen for the calcium transients induced by $1 \mathrm{~Hz}$ stimulation (data not shown). Treating ganglia with $1 \mu \mathrm{M}$ thapsigargin to deplete internal calcium stores had the same effects as with ryanodine (data not shown). The results suggest that calcium-induced calcium release selectively amplifies the cell-wide calcium elevations caused by high-frequency synaptic stimulation and has little effect on the transients attributed to $\alpha 7-\mathrm{nAChR}$ activation.

The ryanodine experiments also provide information about the distribution of receptors contributing to the calcium changes and about the sequence of events that is involved. Ryanodine establishes blockade early on with the protocols used, as demonstrated by the fact that it is already maximally effective in reducing the off-spine calcium signal generated by $50 \mathrm{~Hz}$ stimulation even at the earliest times (Fig. $8 C, D$ ). The fact that ryanodine is unable to reduce the initial calcium elevations on-spine under these conditions although less than one-half of it is generated by $\alpha 7-n A C h R s$ leads to several conclusions. First, the compound seems to have no direct effect on either $\alpha 7$ - or $\alpha 3^{*}$-nAChRs, because both receptor subtypes contribute importantly and directly to the initial increase in on-spine calcium at high-frequency stimulation; second, release from internal stores apparently does not contribute to the initial signal on-spine; and third, essentially all of the cell-wide off-spine signal generated at $50 \mathrm{~Hz}$ arises from L-type channels and internal release with little, if any, coming directly from either $\alpha 7$ - or $\alpha 3^{*}$-nAChRs. This last conclusion is consistent with the known distribution of the receptors from imaging experiments (Shoop et al., 1999).

The strength of the nifedipine and ryanodine experiments depends on the specificity of the compounds. Neither significantly impacted the $\alpha 7-\mathrm{nAChR}$ response, as seen from the calcium signals at $1 \mathrm{~Hz}$. For $\alpha 3^{*}$-nAChRs the specificity was tested directly by incubating dissociated ciliary ganglion neurons in $100 \mathrm{nM}$ $\alpha$-Bgt for $\geq 1$ hr to block $\alpha 7$-nAChRs and then by using whole-cell patch-clamp recording to measure the $\alpha 3^{*}$-nAChR response to 20 $\mu \mathrm{M}$ nicotine before and during exposure to either $10 \mu \mathrm{M}$ nifedipine or ryanodine. Ryanodine had no significant effect on the $\alpha 3^{*}$-nAChR response ( $\leq 5 \%$ inhibition; $n=4$ cells), but nifedipine produced a substantial inhibition $(58 \pm 7 \%$, mean \pm SEM; $n=5$ cells). This raised questions about the mechanism by which nifedipine blocked the sustained calcium increases seen at highfrequency synaptic stimulation.

We examined this further by testing the ability of retrograde stimulation via the postganglionic nerve root to produce sustained cell-wide calcium elevations in the absence of synaptic input. The ganglia were perfused with $20 \mu \mathrm{M}$ D-tubocurarine during such experiments to ensure that no intraganglionic nicotinic signaling (if such exists) could influence the outcome. Retrograde stimulation at $50 \mathrm{~Hz}$ produced a prominent calcium elevation throughout the soma both at on- and off-spine locations (Fig. 9A). The elevation was sustained throughout the period of stimulation and showed no evident decay until stimulation was stopped. Ryanodine treatment significantly reduced the plateau response (Fig. 9B), demonstrating that calcium release from internal stores contributed to the signal. With $1 \mathrm{~Hz}$ stimulation only a small, transient calcium increase was seen either on- or off-spine (Fig. 9C), approximately equivalent to that seen on-spine after the blockade of $\alpha 7$-nAChRs. Ryanodine treatment almost completely blocked the calcium transient induced by retrograde stimulation at $1 \mathrm{~Hz}$ (Fig. 9D). Blockade of the L-type voltage-gated calcium channels with nifedipine completely blocked the calcium elevations induced either by 1 or $50 \mathrm{~Hz}$ retrograde stimulation (Fig. 9E). The fact that nifedipine was more effective than ryanodine at $50 \mathrm{~Hz}$ suggests that L-type channels not only contribute directly to the calcium signal but also may be needed to trigger ryanodinesensitive release from internal stores. In any case, the results indicate that voltage-gated channels and release from internal stores define a pathway for elevating intracellular calcium levels in 
A
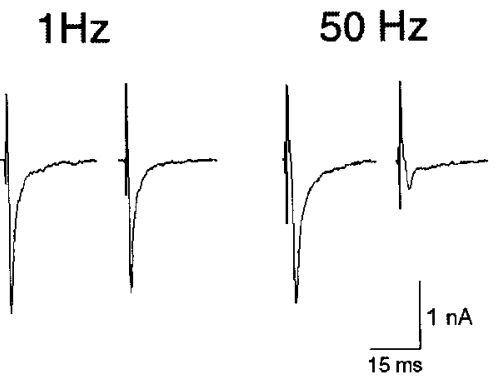

B

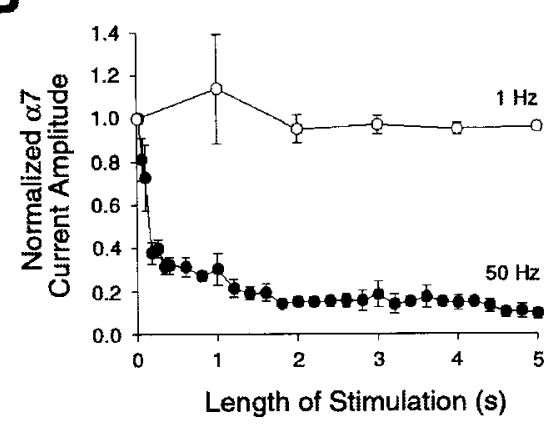

C

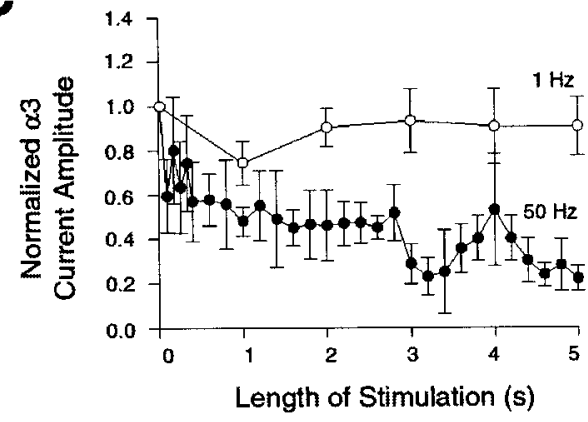

D
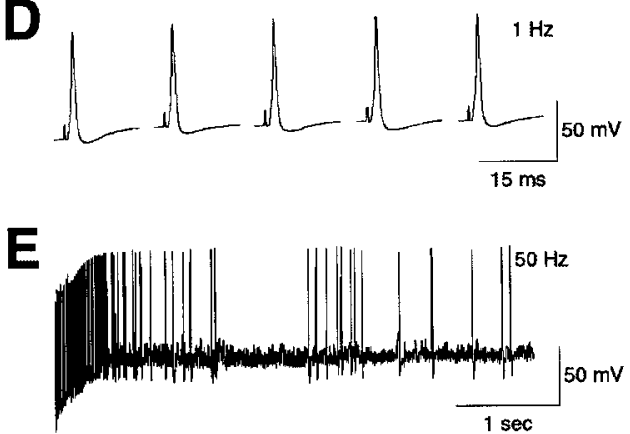

Figure 6. Frequency-dependent changes in synaptic currents and the reliability of synaptic transmission. E15 ganglia were stimulated via the preganglionic nerve root at either 1 or $50 \mathrm{~Hz}$ for $5 \mathrm{sec}$ while the postsynaptic responses were monitored with patch-clamp recording. $A$, Individual synaptic responses recorded in voltage-clamp mode at the beginning and end of the $5 \mathrm{sec}$ stimulation period either at $1 \mathrm{~Hz}$ (left pair) or at $50 \mathrm{~Hz}$ (right pair). No change is seen in the amplitude or time course of the synaptic current after the stimulation period at $1 \mathrm{~Hz}$, but a substantial decrement in amplitude and a change in shape are seen for the synaptic current after $50 \mathrm{~Hz}$. B, Relative amplitude of the $\alpha 7$-nAChR portion of the synaptic current as a function of stimulation time either at $1 \mathrm{~Hz}$ (open circles) or $50 \mathrm{~Hz}$ (filled circles). Values (mean $\pm \mathrm{SEM}$ ) have been normalized to the initial response and are shown at $100 \mathrm{msec}$ intervals for the 1st sec and at $200 \mathrm{msec}$ intervals for the remaining $4 \mathrm{sec}$ of stimulation. A large decline is seen after the first few stimuli at $50 \mathrm{~Hz}$. C, Relative amplitude of $\alpha 3^{*}$-nAChR responses as a function of stimulation time either at $1 \mathrm{~Hz}$ (open circles) or $50 \mathrm{~Hz}$ ( filled circles). Values (mean \pm SEM) have been normalized to the initial response and plotted as in $C$. The $\alpha 3^{*}$-nAChR response declines with stimulation frequency although proportionately not as much as does the $\alpha 7$-nAChR response. $D$, Action potentials elicited by $1 \mathrm{~Hz}$ stimulation for 5 sec and recorded in current-clamp mode. E, Action potentials elicited by $50 \mathrm{~Hz}$ stimulation. No failures were seen at $1 \mathrm{~Hz}$, but a significant incidence of failures is seen at $50 \mathrm{~Hz}$.

the neurons and that repetitive membrane depolarization is sufficient to activate the pathway. High-frequency stimulation of $\alpha 3^{*}$ nAChRs depolarizes the membrane and may well use this same pathway to generate sustained cell-wide calcium increases.

\section{DISCUSSION}

The principal findings reported here are that low-frequency synaptic stimulation triggers calcium transients that are confined to somatic spine mats on ciliary neurons and that the transients are dependent on the activation of $\alpha 7$-nAChRs. High-frequency synaptic stimulation induces sustained cell-wide calcium elevations that can be triggered by $\alpha 3^{*}$-nAChRs and depend on release from internal stores and very likely participation of voltage-gated L-type calcium channels as well. The temporal and spatial differences of the two kinds of patterns offer clear mechanisms by which the neuron could encode information about transmission efficiency and firing frequency, and, as such, enable the neuron to exploit calcium-dependent mechanisms for self-regulation of future signaling capabilities.

The imaging analysis performed here was made possible by the rapid -scanning feature of the recently developed multi-photon laser-scanning microscope and by the distinct topography of the somatic spine mats on ciliary neurons. Because the calcium transients elicited at low-frequency synaptic stimulation rapidly decay, the signal would have been much reduced or missed completely if captured at conventional imaging rates. The fact that the spines are grouped in distinct mats or clumps on the ciliary neuron soma also facilitated the on- versus off-spine quantification. Previous studies have demonstrated that the $\alpha 7-\mathrm{nAChRs}$ are highly concentrated on the spines, that the spines are arranged in discrete mats, and that fluorescent $\alpha$-Bgt labeling of $\alpha 7$-nAChRs is a good marker for spine location (Shoop et al., 1999, 2000). Key for success in correlating the location of spine mats and calcium transients in the present experiments was the fact that the preparation could be held rigidly for the duration with no detectable spatial drift of the cell that was being imaged and the fact that the $\alpha 7$-nAChR density was sufficient to bind adequate fluorescent $\alpha$-Bgt for detection even in the presence of unbound toxin.

A low-affinity calcium fluor was used for the present experiments so that bound calcium would be released quickly and not artificially extend the time courses measured for calcium elevations in the cells. Because of large variations in the efficiency of dye loading, it was not feasible to manipulate the dye level in a controlled way to test directly whether the dye itself constrained the spatial or temporal patterns being reported for the calcium transients. The fact that an L-type channel blocker in the present experiments shortened the time course of decay for the calcium transient, however, suggests that the dye was not rate limiting in determining the duration. The dye previously has been used 

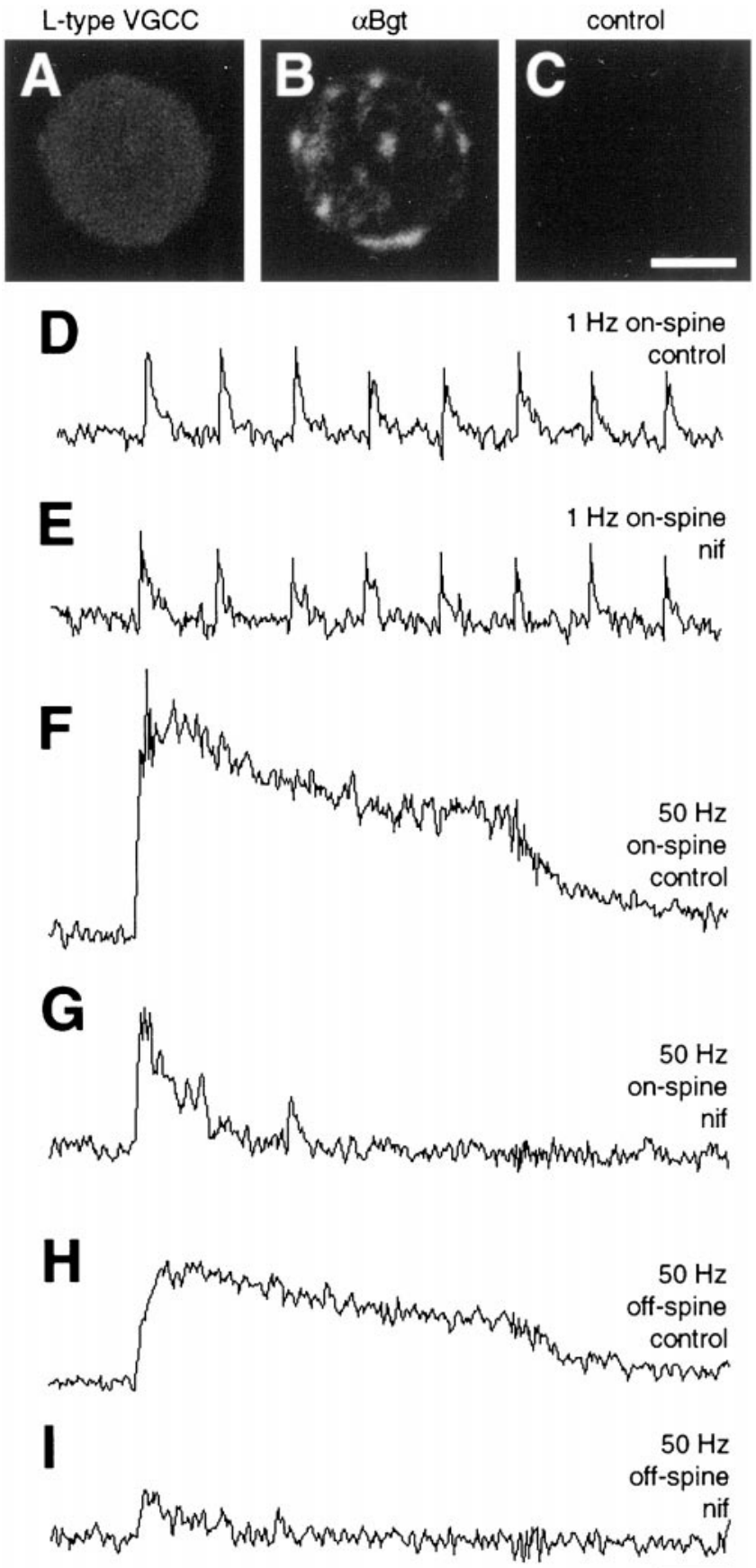

Figure 7. Contribution of voltage-gated L-type calcium channels to synaptically driven calcium elevations. $A$, Immunofluorescent detection of voltage-gated L-type calcium channels on a dissociated E15 ciliary neuron, using an antibody to the $\alpha_{1 c}$ subunit and fluorescent secondary antibody. $B$, Same neuron as in $A$ costained with rhodamine- $\alpha$-Bgt to reveal the $\alpha 7$-nAChRs clusters representing somatic spine mats. $C$, Control showing absence of labeling for an E15 neuron incubated with rabbit IgG instead of the $\alpha_{1 \mathrm{c}}$ antibody. The same gain and exposure times were used for $A-C$. $D-I$, Continuous calcium imaging of on-spine and off-spine regions of a neuron stimulated at 1 or $50 \mathrm{~Hz}$, as indicated, before (control) and after (nif) a 30 min incubation with $10 \mu \mathrm{M}$ nifedipine to block voltage-gated L-type calcium channels. Almost all of the slowly decaying cell-wide calcium elevation was lost when L-type calcium channels were blocked; much of the fast-decaying on-spine calcium transient remained. Similar results were obtained for all nine neurons that were tested. Scale bar for $A-C, 10 \mu \mathrm{m}$; calibration for $D-G, 1 \mathrm{sec}$.
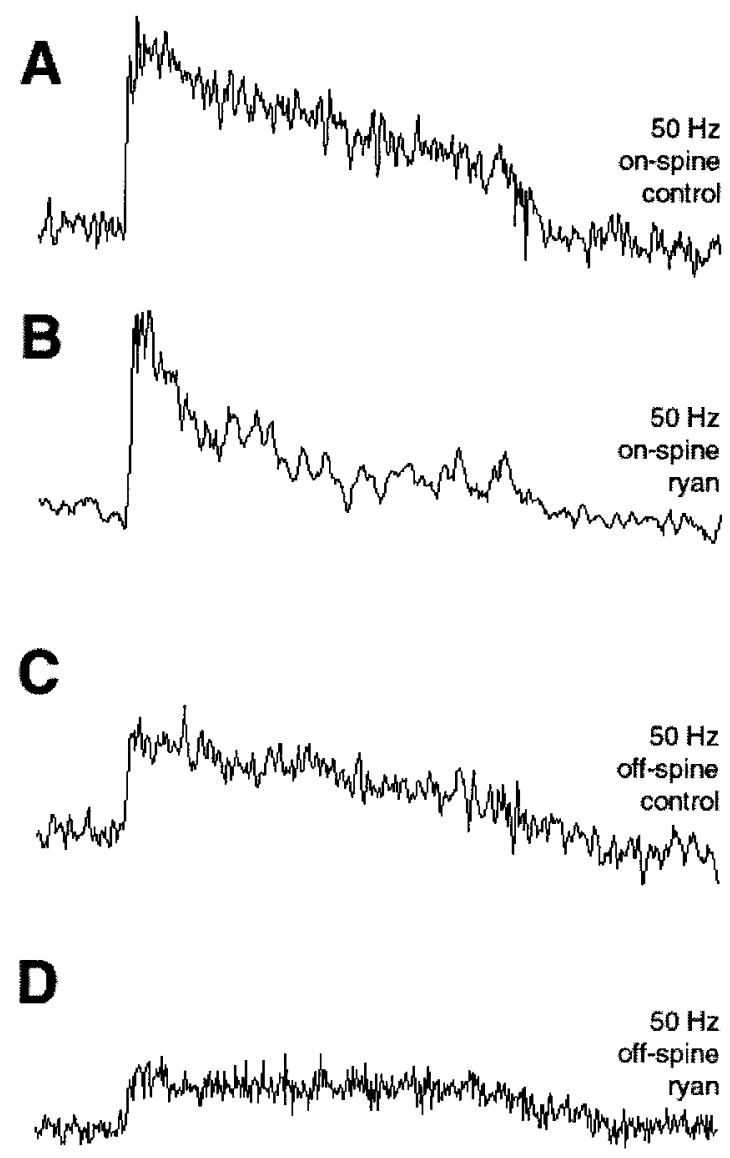

Figure 8. Contribution of release from internal stores to synaptically driven calcium elevations. Shown is continuous calcium imaging of onspine $(A, B)$ and off-spine $(C, D)$ regions of a neuron stimulated at $50 \mathrm{~Hz}$ before (control) and after (ryan) a 30 min incubation with $10 \mu \mathrm{M}$ ryanodine to block calcium release from internal stores. Much of the slowly decaying cell-wide calcium elevation was lost when the release from internal stores was blocked; little effect was seen on the rapidly decaying on-spine response. Similar results were obtained with all 10 neurons that were tested. Calibration, $1 \mathrm{sec}$.

successfully to monitor rapid calcium transients in dendritic spines (Helmchen et al., 1999; Yuste et al., 1999).

The finding that $\alpha 7-n A C h R s$ are responsible for synaptically driven calcium transients in somatic spine mats is consistent with the high relative calcium permeability of the receptors and their being concentrated on the spines (Bertrand et al., 1993; Shoop et al., 1999). The on-spine calcium transients generated by $\alpha 7$ $\mathrm{nAChR}$ activation both at 1 and $50 \mathrm{~Hz}$ appear to be mainly independent of contributions from L-type channels and release from internal stores. At $1 \mathrm{~Hz}$ neither nifedipine nor ryanodine had any effect on the transients although $\alpha$-Bgt almost completely blocked them. At $50 \mathrm{~Hz}$ nifedipine had the most effect, sharply reducing the sustained calcium elevation, but it had little effect on the rapidly decaying $\alpha$-Bgt-sensitive component generated by $\alpha 7$-nAChRs. The nifedipine-resistant component had the same relative peak amplitude (proportion of peak current before treatment) as did the proportion of the control response calculated to be $\alpha$-Bgt-sensitive. A small difference in decay rate was observed for the two, but this could arise either from a small contribution of L-type channels to the rapidly decaying component or from the limitations of calculating a decay constant for a small, rapidly 

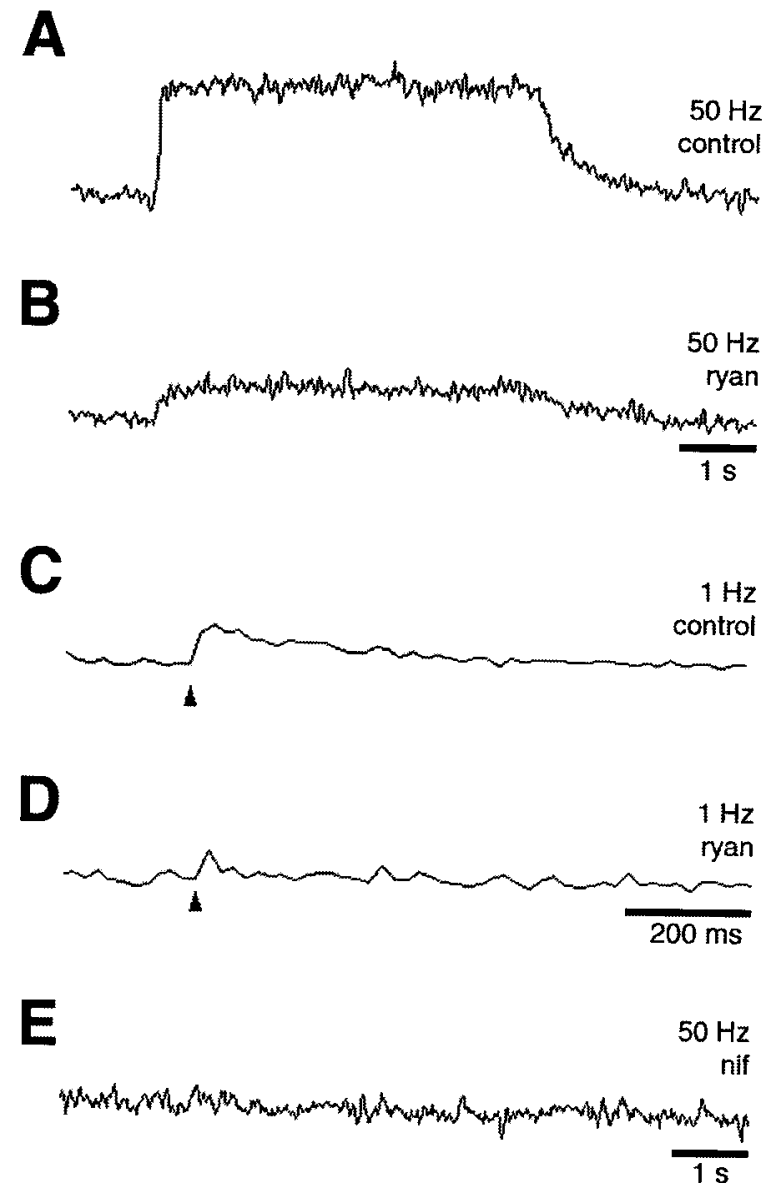

Figure 9. Calcium elevations elicited by retrograde stimulation. E15 ciliary ganglia were backfilled with dye and stimulated in a retrograde manner via the postganglionic nerve root at either 1 or $50 \mathrm{~Hz}$ while individual cells were imaged for calcium fluorescence on-spine. At $50 \mathrm{~Hz}$ the stimulation caused a sustained calcium increase $(A)$ that was blocked substantially by ryanodine $(B)$ and blocked completely at the end of the experiment by nifedipine $(E)$. At $1 \mathrm{~Hz}$ the stimulation produced a small averaged signal (eight responses) on-spine $(C)$ that also was decreased by ryanodine $(D)$. The arrowheads indicate the time of stimulus. Both L-type channels $(n=5$ neurons $)$ and release from internal stores $(n=10$ neurons) contribute substantially to the sustained cell-wide calcium elevations seen at high-frequency stimulation. No difference was seen between on-spine and off-spine regions with respect to calcium increases at either 1 or $50 \mathrm{~Hz}$ retrograde stimulation ( $n=21$ neurons). Calibration: $A$, $B, E, 1 \mathrm{sec} ; C, D, 200 \mathrm{msec}$.

decaying component in the presence of a larger, more slowly decaying one. If L-type channels and calcium stores contribute to local calcium transients in spines, their contributions must be minor compared with that of $\alpha 7$-nAChRs. In fact, the high local concentrations of calcium produced in spines by $\alpha 7-n$ AChRs transiently might inhibit nearby voltage-gated calcium channels (Levitan, 1999). Endoplasmic reticulum has been seen in ciliary spines (Shoop et al., 1999), but it may be more important for calcium buffering.

The sustained cell-wide calcium elevations induced by highfrequency synaptic stimulation depend on $\alpha 3^{*}$-nAChRs, but not on $\alpha 7$-nAChRs, because the elevations can be blocked by D-tubocurarine, but not by $\alpha$-Bgt. Although $\alpha 3^{*}$-nAChRs are much less abundant than are $\alpha 7-\mathrm{nAChRs}$, they are distributed more widely, being found both on spines and at postsynaptic densities on the soma (Jacob et al., 1984; Wilson Horch and Sargent, 1995;
Williams et al., 1998; Shoop et al., 1999). The present measurements could not resolve the site of origin for the sustained calcium elevations; the speed of image collection was considerable, but not sufficient to distinguish differences in the rates of rise for calcium increases at different points along the cell surface.

The role of $\alpha 3^{*}$-nAChRs in generating the sustained calcium elevations may be primarily that of a catalyst, acting to depolarize the membrane. Depolarizing the membrane would activate L-type calcium channels, and these, in turn, apparently can induce calcium release from internal stores, as the retrograde stimulation experiments demonstrate. The immunofluorescence staining of L-type channels showed that they are distributed all over the ciliary neuron soma, and membrane compartments likely to serve as sites of calcium release can be found throughout the soma as well (Pilar and Landmesser, 1976; Jacob and Berg, 1988). A second mode of action for $\alpha 3^{*}$-nAChRs that cannot be excluded yet (given the partial inhibition of the receptors by nifedipine in the present experiments) is that they may permit sufficient calcium influx themselves to trigger some calcium-induced calcium release from internal stores.

Calcium imaging in chick ciliary ganglion neurons in situ has been used previously to examine the rate at which calcium levels in the neurons return to normal after varying periods of highfrequency stimulation (Brain and Bennett, 1998). The instrumentation that was used would not have detected the rapid on-spine calcium transients reported here, but the study was able to consider in some detail the mechanisms influencing calcium release from internal stores and those responsible for returning calcium levels to baseline in ciliary neurons (Brain and Bennett, 1998). Recovery was not examined in the present study, other than to determine mean time constants for return to baseline after $50 \mathrm{~Hz}$ stimulation. The fact that very little decrement occurred in the cell-wide calcium increase during the $5 \mathrm{sec}$ stimulation at $50 \mathrm{~Hz}$ demonstrates the stamina of the signaling system.

What might be the purpose of synaptically driven calcium signaling in ciliary ganglion neurons? One possibility is that it helps to guide developmental events. Spontaneous bursting activity has been reported in a number of developing systems, including the visual system and the somatic motor pathway, and it has been postulated to shape neuronal development and circuit formation (Feller, 1999; Milner and Landmesser, 1999). It is not known whether spontaneous bursting activity occurs in the ciliary ganglion during embryogenesis, but the fact that the ganglion represents a motor pathway makes this a consideration. The mature calyx synapse also can support high-frequency signaling (Dryer, 1994), but it is not known how often the synapse is called on to do so in vivo. The present results indicate that high-frequency signaling can produce sustained cell-wide calcium elevations, raising the possibility of excitotoxicity. Chronic exposure in ovo to nicotinic antagonists in general and $\alpha$-Bgt in particular have pronounced and complex effects on neuronal survival and development in the ciliary ganglion (Meriney et al., 1987). It has not yet been possible, however, to dissect unambiguously the contributions of ganglionic receptors and peripheral muscle receptors to these events.

The fact that the synaptically driven calcium transients persist into posthatch chicks and retain many of the features seen earlier during development suggests that the calcium signaling may play a regulatory role in the mature system. An attractive possibility is that synaptically driven calcium transients in the ciliary ganglion regulate synaptic plasticity, as is the case in the CNS. Several forms of synaptic plasticity have been reported for the calyx synapse on ciliary neurons; these include facilitation, post-tetanic 
potentiation (PTP), and long-term potentiation (LTP; Martin and Pilar, 1964b; Poage and Zengel, 1993; Scott and Bennett, 1993a,b; Brain and Bennett, 1995). In addition, $\alpha 7$-nAChRs on ciliary ganglion neurons undergo activity-dependent rundown, as do NMDA receptors on hippocampal spines, and the rundown depends on calcium influx and the ensuing balance of activities between calcium/calmodulin-dependent protein kinase II and calcineurin (Liu and Berg, 1999a). Thus calcium transients in somatic spines may act locally to regulate signal detection in the spine over the short term. Local calcium transients also may influence the shape or stability of the spine itself, as demonstrated for dendritic spines (for review, see Segal et al., 2000). Over the long range, synaptically driven changes in calcium levels could regulate gene expression (Mermelstein et al., 2000). Understanding these processes may provide information about nicotinic signaling elsewhere in the nervous system and offer new insight into the many functions of spines, whether dendritic or somatic.

\section{REFERENCES}

Bertrand D, Galzi JL, Devillers-Thiery A, Bertrand S, Changeux J-P (1993) Mutations at two distinct sites within the channel domain $\mathrm{M}_{2}$ alter calcium permeability of neuronal $\alpha 7$ nicotinic receptor. Proc Natl Acad Sci USA 90:6971-6975.

Brain KL, Bennett MR (1995) Calcium in the nerve terminals of chick ciliary ganglia during facilitation, augmentation, and potentiation. J Physiol (Lond) 489:637-648.

Brain KL, Bennett MR (1998) Calcium transients evoked by action potentials in the somata of chick ciliary neurons. J Auton Nerv Syst 71:120-133.

Chang K, Berg DK (1999) Dependence of circuit function on nicotinic acetylcholine receptors containing $\alpha 7$ subunits. J Neurosci 19:3701-3710.

Chiappinelli VA (1983) Kappa-bungarotoxin: a probe for the neuronal nicotinic receptor in the avian ciliary ganglion. Brain Res 277:9-21.

Choi DW (1992) Excitotoxic cell death. J Neurobiol 23:1261-1276.

Couturier S, Bertrand D, Matter J-M, Hernandez M-C, Bertrand S, Millar N, Valera S, Barkas T, Ballivet M (1990) A neuronal nicotinic acetylcholine receptor subunit $(\alpha 7)$ is developmentally regulated and forms a homo-oligomeric channel blocked by $\alpha$-Btx. Neuron 5:847-856.

Dryer S (1994) Functional development of the parasympathetic neurons of the avian ciliary ganglion: a classic model system for the study of neuronal differentiation and development. Prog Neurobiol 43:281-322.

Fan GY, Fujisaki H, Miyawaki A, Tsay RK, Tsien RY, Ellisman MH (1999) Video-rate scanning two-photon excitation fluorescence microscopy and ratio imaging with cameleons. Biophys J 76:2412-2420.

Feller MB (1999) Spontaneous correlated activity in developing neural circuits. Neuron 22:653-656.

Harris KM (1999) Structure, development, and plasticity of dendritic spines. Curr Opin Neurobiol 9:343-348.

Helmchen F, Svoboda K, Denk W, Tank DW (1999) In vivo dendritic calcium dynamics in deep-layer cortical pyramidal neurons. Nat Neurosci 2:989-996.

Jacob MH, Berg DK (1983) The ultrastructural localization of $\alpha$-bungarotoxin binding sites in relation to synapses on chick ciliary ganglion neurons. J Neurosci 3:260-271.

Jacob MH, Berg DK (1988) The distribution of acetylcholine receptors in chick ciliary ganglion neurons following disruption of ganglionic connections. J Neurosci 8:3838-3849.

Jacob MH, Berg DK, Lindstrom JM (1984) Shared antigenic determinant between the Electrophorus acetylcholine receptor and a synaptic component on chicken ciliary ganglion neurons. Proc Natl Acad Sci USA 81:3223-3227.

Koch C, Zador A (1993) The function of dendritic spines: devices subserving biochemical rather than electrical compartmentalization. J Neurosci 13:413-422.

Levitan IB (1999) It is calmodulin after all! Mediator of the calcium modulation of multiple ion channels. Neuron 22:645-648.

Liu Q-S, Berg DK (1999a) Actin filaments and the opposing actions of $\mathrm{CaM}$ kinase II and calcineurin in regulating $\alpha 7$-containing nicotinic receptors on chick ciliary ganglion neurons. J Neurosci 19:10280-10288.

Liu Q-S, Berg DK (1999b) Extracellular calcium regulates the responses of both $\alpha 3$ - and $\alpha 7$-containing nicotinic receptors on chick ciliary ganglion neurons. J Neurophysiol 82:1124-1132.

Malenka RC, Nicoll RA (1999) Long-term potentiation-a decade of progress? Science 285:1870-1874.
Martin AR, Pilar G (1964a) An analysis of electrical coupling at synapses in the avian ciliary ganglion. J Physiol (Lond) 171:454-475.

Martin AR, Pilar G (1964b) Presynaptic and postsynaptic events during post-tetanic potentiation and facilitation in the avian ciliary ganglion. J Physiol (Lond) 175:17-30.

McNerney ME, Pardi D, Pugh PC, Nai Q, Margiotta JF (2000) Expression and channel properties of $\alpha$-bungarotoxin-sensitive nicotinic acetylcholine receptors on chick ciliary and choroid neurons. J Neurophysiol 84:1314-1329.

Meriney SD, Pilar G, Ogawa M, Nunez R (1987) Differential neuronal survival in the avian ciliary ganglion after chronic acetylcholine receptor blockade. J Neurosci 7:3840-3849.

Mermelstein PG, Bito H, Deisseroth K, Tsien RW (2000) Critical dependence of cAMP response element-binding protein phosphorylation on L-type calcium channels supports a selective response to EPSPs in preference to action potentials. J Neurosci 20:266-273.

Milner LD, Landmesser LT (1999) Cholinergic and GABAergic inputs drive patterned spontaneous motoneuron activity before target contact. J Neurosci 19:3007-3022.

Muller W, Connor JA (1991) Dendritic spines as individual neuronal compartments for synaptic $\mathrm{Ca}^{2+}$ responses. Nature 354:73-76.

Pilar G, Landmesser L (1976) Ultrastructural differences during embryonic cell death in normal and peripherally deprived ciliary ganglia. J Cell Biol 68:339-356.

Poage RE, Zengel JE (1993) Kinetic and pharmacological examination of stimulation-induced increases in synaptic efficacy in the chick ciliary ganglion. Synapse 14:81-89.

Rathouz MM, Vijayaraghavan S, Berg DK (1996) Elevation of intracellular calcium levels in neurons by nicotinic acetylcholine receptors. Mol Neurobiol 12:117-131.

Schoepfer R, Conroy WG, Whiting P, Gore M, Lindstrom J (1990) Brain $\alpha$-bungarotoxin binding protein cDNAs and mAbs reveal subtypes of this branch of the ligand-gated ion channel gene superfamily. Neuron 5:35-48.

Scott TRD, Bennett MR (1993a) The effect of ions and second messengers on long-term potentiation of chemical transmission in avian ciliary ganglia. Br J Pharmacol 110:461-469.

Scott TRD, Bennett MR (1993b) The effect of nitric oxide on the efficacy of synaptic transmission through the chick ciliary ganglion. $\mathrm{Br} \mathrm{J}$ Pharmacol 110:627-632.

Segal M, Korkotian E, Murphy DD (2000) Dendritic spine formation and pruning: common cellular mechanisms? Trends Neurosci 23:53-57.

Seguela P, Wadiche J, Dineley-Miller K, Dani JA, Patrick JW (1993) Molecular cloning, functional properties, and distribution of rat brain $\alpha 7$ : a nicotinic cation channel highly permeable to calcium. J Neurosci 13:596-604.

Shoop RD, Martone ME, Yamada N, Ellisman MH, Berg DK (1999) Neuronal acetylcholine receptors with $\alpha 7$ subunits are concentrated on somatic spines for synaptic signaling in embryonic chick ciliary ganglia. J Neurosci 19:692-704.

Shoop RD, Yamada N, Berg DK (2000) Cytoskeletal links of neuronal acetylcholine receptors containing $\alpha 7$ subunits. J Neurosci 20:4021-4029.

Svoboda K, Tank DW, Denk W (1996) Direct measurement of coupling between dendritic spines and shafts. Science 272:716-719.

Tsien RY, Bacskai BJ (1995) Video-rate confocal microscopy. In: Handbook of biological confocal microscopy (Pawley JB, ed), pp 459-487. New York: Plenum.

Ullian EM, McIntosh JM, Sargent PB (1997) Rapid synaptic transmission in the avian ciliary ganglion is mediated by two distinct classes of nicotinic receptors. J Neurosci 17:7210-7219.

Vernallis AB, Conroy WG, Berg DK (1993) Neurons assemble acetylcholine receptors with as many as three kinds of subunits while maintaining subunit segregation among receptor subtypes. Neuron 10:451-464.

Williams BM, Tamburni MK, Schwartz Levey M, Bertrand S, Bertrand D, Jacob MH (1998) The long internal loop of the $\alpha 3$ subunit targets nAChRs to subdomains within individual synapses on neurons in vivo. Nat Neurosci 1:557-562.

Wilson Horch HL, Sargent PB (1995) Perisynaptic surface distribution of multiple classes of nicotinic acetylcholine receptors on neurons in the chicken ciliary ganglion. J Neurosci 15:7778-7795.

Yuste R, Denk W (1995) Dendritic spines as basic functional units of neuronal integration. Nature 375:682-684.

Yuste R, Majewska A, Cash SS, Denk W (1999) Mechanisms of calcium influx into hippocampal spines: heterogeneity among spines, coincidence detection by NMDA receptors, and optical quantal analysis. J Neurosci 19:1976-1987.

Zhang Z-W, Coggan JS, Berg DK (1996) Synaptic currents generated by neuronal acetylcholine receptors sensitive to $\alpha$-bungarotoxin. Neuron 17:1231-1240. 